Un paseo cultural por la representación de palermo en la narrativa de Giuseppina Torregrossa

\title{
LA CIUDAD COMO MARCO IDENTITARIO DE SICILIA: UN PASEO CULTURAL POR LA REPRESENTACIÓN DE PALERMO EN LA NARRATIVA DE GIUSEPPINA TORREGROSSA ${ }^{1}$
}

\author{
José García Fernández² \\ Universidad de Oviedo (España) \\ garciafernandezjose@uniovi.es
}

Recibido: 25/04/2020 - Aprobado: 02/06/2020 - Publicado: 15/04/2021

DOI: doi.org/10.17533/udea.lyl.n79a19

\begin{abstract}
Resumen: Giuseppina Torregrossa se sirve de su producción narrativa para representar antropológicamente su ciudad natal: Palermo. Marco espacial de siete de sus novelas, la capital siciliana aparece encarnada a través de múltiples protagonistas que exploran su rol social dentro de la isla. Haciendo un paseo cultural por Sicilia, este artículo se centra en el análisis históricoliterario de Palermo — e incluso de su provincia - a partir de las descripciones etnográficas realizadas por Torregrossa en $\mathrm{Il}$ conto delle minne, Il figlio maschio, La miscela segreta di casa Olivares, Cortile Nostalgia, Panza e prisenza, Il basilico di Palazzo Galletti e Il sanguinaccio dell'Immacolata.

Palabras clave: Giuseppina Torregrossa; literatura románica; historia de Italia; sicilianidad; antropología urbana.

\section{THE CITY AS SICILY'S IDENTITY FRAMEWORK: A CULTURAL JOURNEY THROUGH THE REPRESENTATION OF PALERMO IN GIUSEPPINA TORREGROSSA'S NARRATIVE}

\begin{abstract}
Giuseppina Torregrossa uses her narrative production to portray the anthropological features of her birthplace: Palermo. The Sicilian capital becomes the framework of seven of her novels and is represented through the social roles of several of Torregrossa's main characters. The article's main aim is to make a cultural journey through the historical and literary analysis of Palermo - as well as its province - on the basis of Torregrossa's ethnographic depictions that are found in Il conto delle minne, Il figlio maschio, La miscela segreta di casa Olivares, Cortile Nostalgia, Panza e prisenza, Il basilico di Palazzo Galletti, and Il sanguinaccio dell'Immacolata.
\end{abstract}

Key words: Giuseppina Torregrossa; Romance literature; history of Italy; Sicilianness; urban anthropology.

\footnotetext{
1. La publicación de este artículo ha sido posible gracias a la obtención de una ayuda postdoctoral (núm. de referencia PA-17-PFBP16053) del Programa «Severo Ochoa» para la formación en investigación y docencia del Principado de Asturias (España).

2. Este trabajo ha sido desarrollado gracias a la obtención de una ayuda postdoctoral del Programa «Severo Ochoa» para la formación en investigación y docencia del Principado de Asturias (España). Un sincero agradecimiento al Dr. Francisco Martín Miguel, filólogo y compañero de la Facultad de Filosofía y Letras de la Universidad de Oviedo, cuyos comentarios y recomendaciones han contribuido a enriquecer notablemente el borrador inicial de este artículo.
} 


\section{Introducción}

ún siendo consciente de las fuertes contradicciones que definen su ciudad natal, la palermitana Giuseppina 1 Torregrossa (1956-) siempre ha forjado un profundo vínculo con su localidad de origen. Este apego $\angle$ por la capital siciliana —extrapolable al conjunto del territorio insular - se plasma con todo detalle en el marco espacial de su producción narrativa. Sicilia se erige como el núcleo central sobre el que pivotan las creaciones literarias de Torregrossa, volúmenes en los que los enclaves sicilianos —piénsese en Caltanissetta, Castelbuono, Catania, Cefalù, Corleone, Gangi, La Playa, Malavacata, Roccabusambra, Scopello, Sommatino, Strafalcello, Taormina o Tummìna - atraen el foco de atención de la autora.

Analizadas desde un punto de vista crítico, social y cultural, estas poblaciones isleñas permiten a Torregrossa representar literariamente su región de procedencia, un emplazamiento en el que Palermo ocupa un lugar central. Atenta a la evolución y al desarrollo colectivos de la capital siciliana, Torregrossa se vale de sus libros para describir de forma pormenorizada la historia de Palermo desde su anexión al estado italiano hasta la actualidad. A este respecto, cabe resaltar cómo el examen concienzudo de la ambientación de siete de sus novelas se revela seminal, pues contribuye a puntualizar los rasgos definitorios de una ciudad cuya idiosincrasia ha sido fuente de inspiración para literatas contemporáneas como Marilena Monti, Valentina Gebbia o Stefania Auci.

No obstante, la riqueza que aporta Torregrossa a la representación histórico-literaria de Palermo se concentra en las figuras narrativas de sus relatos: los personajes que protagonizan sus textos —en su mayoría mujeres- son los verdaderos partícipes de los cambios antropológicos experimentados por la urbe a lo largo de los últimos 160 años. De ahí que, de acuerdo con esta original técnica literaria, este artículo: 1) persiga realizar un paseo cultural por Palermo con el fin de arrojar datos atinentes a la historia comunitaria de sus residentes - y, por extensión especular, de Sicilia-; y 2) pretenda sacar a la luz el modo en el que las féminas han logrado prosperar dentro de la conservadora sociedad palermitana.

Para lograr el cumplimiento de estos objetivos, además de fijarse en cuáles son las tramas narrativas en las que Palermo desempeña un rol primario y fundamental, resulta asimismo imprescindible la ordenación de las novelas de Torregrossa según el momento cronológico en el que se producen los acontecimientos de sus tramas. Así pues, a nivel metodológico, este estudio literario comienza con el análisis del argumento de Il conto delle minne, una narración de 2009 en la que se desgranan los sinsabores padecidos por un movimiento obrero siciliano de finales del siglo XIx: Los Fasci siciliani. ${ }^{3}$

El acercamiento a esta coyuntura temporal sirve para introducir las singularidades etnográficas de Palermo presentes en Il figlio maschio (2015), volumen donde el retrato literario de la vida de Filippo, personaje clave de la obra, permite a la autora abordar los comportamientos propios de la época dictatorial mussoliniana. Como broche final a este oscuro periodo de la historia italiana, La miscela segreta di casa Olivares (2013) afronta las angustias que atenazaron a los palermitanos durante la Segunda Guerra Mundial, así como las dificultades que acarrearon

3. Il conto delle minne también aporta datos significativos sobre la especulación inmobiliaria y sobre el aperturismo femenino propios de Palermo desde los años cincuenta del siglo pasado. 
Un paseo cultural por la representación de palermo en la narrativa de Giuseppina Torregrossa para la población siciliana el fin de la dictadura de Mussolini y la instauración de la República Italiana en 1946.

De todos modos, la alusión a las contrariedades sufridas por los habitantes de Palermo no concluye aquí: en Cortile Nostalgia (2017), el barrio palermitano de Albergheria se erige como el eje temático sobre el que giran los sucesos reseñados en el libro, una obra en la que se concretan los obstáculos superados por múltiples palermitanos desde los inicios de la República hasta finales de la década de los setenta del siglo pasado. Por otro lado, la ciudad de Palermo también aparece personificada por la comisaria Marò Pajno. Protagonista de Panza e prisenza (2012), Il basilico di Palazzo Galletti (2018) e Il sanguinaccio dell'Immacolata (2019), esta mujer encarna los valores identitarios de la actual Sicilia. Su trabajo como agente de policía evidencia la paulatina transformación de la sociedad palermitana e isleña, una comunidad que, como ella misma corrobora, en ocasiones es víctima de su inveterado pasado.

\section{La representación histórico-etnográfica de Palermo}

Ateniéndose a la metodología explicada en el punto precedente, este apartado se detiene en la descripción de Palermo desde finales del siglo XIX hasta la actualidad. Para llevar a cabo este análisis literario de tipo histórico y etnográfico, los textos de Torregrossa se agruparán en tres grandes bloques cronológicos: 1) los relativos al periodo decimonónico posterior a la Unificación de Italia, o bien a la etapa mussoliniana; 2) los centrados en la época que abarca desde el final del totalitarismo itálico hasta los «años de plomo»; y 3) los atinentes a la era contemporánea.

\subsection{Del periodo decimonónico al mussoliniano}

Acontecida en diversos enclaves sicilianos - a pesar de que la trama concluye en Barcelona-, la novela Il conto delle minne (2010 [2009]) concede un pequeño espacio narrativo a la matanza de los Fascios acaecida en la localidad palermitana de Catalvuturo. La provincia de Palermo y el conjunto de Sicilia se distinguiría a finales del siglo XIX por la constitución de una comunidad de trabajadores que decidió luchar por la mejora de sus derechos sociales y laborales. Las clases más desfavorecidas procuraron saciar su hambre individual y colectiva a través del respaldo de unas mejores condiciones de vida. Sin embargo, estas demandas se tradujeron en una intervención del ejército que conduciría, entre otras consecuencias, a la muerte de numerosos individuos en Catalvuturo a comienzos de 1893 (Giangrande, 2016, p. 297). La funesta reacción de la que fueron partícipes las masas trabajadoras palermitanas se saldó con múltiples homicidios, fallecimientos a los que se hace mención expresa en la narrativa de Torregrossa (2010 [2009], p. 32).

Sirviéndose de Luisa, personaje de Il conto delle minne, Torregrossa hace referencia a las Ligas Sicilianas de los Trabajadores, un movimiento de índole socialdemócrata que, como apunta Ceruso en I 100 delitti della Sicilia (2015), se caracterizó por ser una revuelta vinculada a la tierra, a las reivindicaciones sociales, a la mafia, pero 
Un paseo cultural por la representación de palermo en la narrativa de Giuseppina Torregrossa

que también surgió como respuesta a un estado que se había convertido en un instrumento al servicio de la clase dominante. Aun así, la población todavía no era consciente de la opresión que años más tarde representaría el triunfo de los ideales mussolinianos. Filippo, personaje clave de la trama de Il figlio maschio, encarna ese oscuro periodo de la historia italiana. Representante de la Editorial Vallecchi, fue miembro de una empresa que no solo se mostraría afín al fascismo, sino que sería igualmente valorada por personalidades de la talla de Francesco Ciarlantini (1885-1940). En relación con esto, Lecco (1981) apuntó:

Nel febbraio del 1923, dopo essersi iscritto al Partito nazionale fascista; il C[iarlantini] entrò a far parte del Direttorio nazionale del partito e del Gran Consiglio del fascismo; diresse, tra il '23 e il '24, l'Ufficcio stampa e propaganda. Venne eletto deputato nella XXVII legislatura (1924-1929) e qui fece sentire la sua voce, partecipando all'elaborazione di numerosi disegni di legge, svolgendo interrogazioni parlamentari, presentando osservazioni e proposte (pp. 214-216).

Personificando el estado fascista italiano con la ayuda de Filippo y de una editorial próxima a la ideología mussoliniana, Torregrossa explicita las características de una etapa histórica crucial en el devenir de Italia. El hecho de citar la Editorial Vallecchi permite conectar el tejido narrativo con figuras como Ciarlantini, director entre 1923-1924 de la oficina de impresión y propaganda del estado. Il figlio maschio proporciona suficientes herramientas textuales para esgrimir la situación de Palermo durante la dictadura. La librería que Filippo abriría frente al Teatro Massimo así lo atestigua. García Fernández (2019) así lo reflejó en su monografía:

En este nuevo local no faltaron signos fascistas —en la parte superior de las estanterías de la sala de lectura figuraba el aforismo libro e moschetto fascista perfetto - ni tampoco libros afines al régimen mussoliniano, dos aspectos que pusieron de relieve la importancia del adoctrinamiento político y el papel que la industria editorial jugaba en dicha instrucción (p. 261).

Filippo se había convertido en un distinguido editor, en un empresario que incluyó en su negocio uno de los eslóganes con los que se pretendía ensalzar el gran poder de la nación italiana. La relevancia de los libros en el adoctrinamiento de la población y el papel preponderante de las armas en la defensa de Italia se erigían como los pilares fundamentales del perfecto fascista mussoliniano, un protohombre que Filippo procuraría realzar y promulgar desde los estantes de su propia librería. Y si bien Filippo se hizo un hueco dentro de la burguesía palermitana, terminaría falleciendo con prontitud, resultado, por otra parte, de los conflictos habidos en el país durante la Segunda Guerra Mundial.

\subsection{Del fin del totalitarismo itálico a los «años de plomo»}

Ambientada en los Quattro Mandamenti de Palermo, la novela La miscela segreta di casa Olivares (2015 [2013]) se enmarca dentro de uno de los más alegóricos símbolos urbanísticos de Palermo y se desarrolla en uno de los momentos más decisivos de la reciente historia italiana: la década de los cuarenta del siglo pasado. Centrándose en la vida de Genziana, protagonista del relato, Torregrossa narra en esta obra las vicisitudes de una mujer que llegaría a ser la máxima responsable de la empresa cafetera de su padre, un hecho que denotaría su coraje al ocupar un rol profesional antaño vedado al género femenino. 
Un paseo cultural por la representación de palermo en la narrativa de Giuseppina Torregrossa

No es de extrañar, por tanto, que el arrojo y la audacia de Genziana sirviesen de inspiración a su progenitor, Roberto Olivares, quien llegó a crear una variedad de café con el nombre de su hija (Torregrossa, 2015 [2013], p. 279). Aunando en su persona las más insignes virtudes masculinas y femeninas, la mezcla del café robusta y arábica recreaba con acierto el carácter y la personalidad de Genziana. La invención de esta miscelánea una mezcla que, además, da título a la novela- permitiría que dos tipos de café a priori antagónicos pudieran fusionarse de un modo único e inimitable.

Pensando en Genziana y en sus magníficas cualidades, Roberto supo potenciar las propiedades más emblemáticas de cada variedad cafetera para obtener un resultado inigualable. Por muy contraproducente que le resultara esta simbiosis antipatriarcal, su hija era la confirmación de que las mujeres también están dotadas de habilidades que no las reducen en exclusiva al ámbito doméstico, sino que les permiten igualmente ser partícipes del ámbito profesional isleño. De ahí que, dejando a un lado la cosmovisión identitaria patriarcal de Roberto, el negocio familiar lograse obtener el monopolio del café en la capital siciliana. El «Caffè Genziana» no tenía competidor alguno en el Palermo previo a la Segunda Guerra Mundial, un momento histórico en el que esta metrópoli aún daba muestras de su ancestral resplandor:

\footnotetext{
Palermo era a quei tempi una signora aristocratica, dalle guance rosee, le labbra tumide, il volto espressivo, gli occhi languidi. Adagiata ai piedi di montagne protettive, bagnata da un mare salato e dolce al tempo stesso, si compiaceva della propria bellezza. Gli abitanti erano sottomessi, ma non asserviti. C'era margine per solidarietà e fratellanza, e la parola «famiglia» non aveva ancora un suono sinistro. [...] Palermo non era più «felicissima», ma era ancora una città felice (Torregrossa, 2015 [2013], p. 35).
}

Como se deduce de estas palabras, Palermo todavía apelaba a su atávico linaje aristocrático, palpable, por otra parte, en la extraordinaria belleza de una urbe no solo protegida por las montañas, sino también bañada por un mar agridulce. La población vivía con relativa felicidad y no se sentía esclava o presa de sí misma. En el periodo prebélico aún había espacio para el compañerismo y la fraternidad, y las relaciones de parentesco tampoco eran el desencadenante de caóticas e impredecibles situaciones. Sin embargo, el apoyo de Italia al gobierno hitleriano durante la Segunda Guerra Mundial trajo nefastas consecuencias para Palermo. Madre de Genziana y cafeomante de profesión, Viola Olivares vaticinó el cruento destino itálico tras contemplar los posos de una taza de café. Se percató entonces de que Italia acabaría viéndose envuelta en un serio conflicto que dejaría desgarradoras secuelas en Palermo. Así fue: tal y como Melograni trata en Italia in guerra (2010), Mussolini anunciaría el 10 de junio de 1940 la entrada del país en el Segundo Conflicto Bélico Mundial.

Declarada la guerra a Gran Bretaña y a Francia, la ciudad de Palermo experimentó el 23 de junio de 1940 los efectos derivados del inicio de esta contienda, una jornada en la que, como exponen Bellomo y Picciotto en su obra Bombe su Palermo (2016), caería el primer artefacto sobre la urbe. Y si bien no hubo víctimas (Torregrossa, 2015 [2013], p. 90), la población vivió en máxima alerta a partir de ese instante. Esta embrollada coyuntura ponía a prueba el vigor y la entereza de los palermitanos, sacando a la luz sus más preciadas capacidades, aunque también sus más profundos defectos.

La situación llegaría a ser extrema y su resultado más palmario fue una hambruna generalizada. Lejos de 
Un paseo cultural por la representación de palermo en la narrativa de Giuseppina Torregrossa

nutrir los contactos sociales, los bombardeos que se sucedieron en Palermo el 23 de enero y el 18 de abril de 1943 presagiaban un trágico destino para Genziana y para su familia, todo lo cual queda recogido por la autora como sigue:

Non c'è modo di scegliere quando né dove finire i nostri giorni: se ne accorsero il 9 maggio del 1943 i palermitani che [come i genitori di Genziana e sua nonna materna, Ortensia] morirono al rifugio di piazzetta Sett'Angeli, proprio quando la guerra sembrava alla fine (Torregrossa, 2015 [2013], p. 126).

El 9 de mayo de 1943 pasó así a ser una fecha clave en el devenir de Genziana y de tantos otros palermitanos y sicilianos que, como Bellomo plasma en 1943. Il martirio di un'isola (2016), aquel día vieron quebrada su existencia.

Huérfana, Genziana debía recomponer las riendas de su vida. Y en consonancia con el estado de quebranto y de entereza que entonces destilaba Palermo, ${ }^{4}$ la joven procuró resurgir de sus cenizas: la ciudad de Palermo había quedado completamente arrasada (Torregrossa, 2015 [2013], pp. 127-128), como también derrotada se hallaba Genziana tras haber perdido a su abuela y a sus progenitores con tan solo diecisiete años. Gracias al armisticio firmado por Italia con las Fuerzas Aliadas el 3 de septiembre de 1943, Palermo pudo vivir por fin más tranquila y sus ciudadanos se aprestaron a reconstruir la ciudad. Los palermitanos reaccionaban con sensatez a fin de recuperar su anhelada cotidianidad, una manera de actuar que llevaría ineludiblemente a Genziana a tomar las riendas de su vida como mujer.

En esta nueva faceta vital de la protagonista, Torregrossa plasma su amor por Medoro, un joven palermitano vinculado al mundo de la política que pronto la convenció para apoyar la república en las elecciones del 2 de junio de 1946. De enorme calado, dichos comicios tuvieron una trascendental significación para la reciente historia de Italia, pues, además de decidirse el futuro sistema gubernamental del estado, fueron los primeros en los que a las mujeres italianas se les permitió ejercer su derecho al voto. No obstante, este «aperturismo» legal e ideológico no satisfizo a muchos palermitanos, quienes, afines a los tradicionales valores sicilianos, no vieron con buenos ojos que los votos de sus hijas o de sus esposas tuvieran validez alguna:

I palermitani, che di fronte ai cambiamenti tirano calci come $i$ muli nella muntata, cominciarono a paventare una catastrofe peggiore della guerra. Perciò in molti, la notte prima del voto, rinchiusero le mogli e le sorelle dentro casa.

[...] Ma i lucchetti non bastarono a frenare le donne, che all'alba si trovarono tutte davanti ai seggi (Torregrossa, 2015 [2013], p. 179).

Pese a las trabas de sus padres o maridos, las palermitanas no sucumbieron a las concepciones del patriarcado isleño: muchas sicilianas empezaban ahora a percatarse de su auténtica valía personal, de modo que, como examinan Rossi-Doria en Diventare cittadine (1996) y Sarlo y Zajczyk en Dove batte il cuore delle donne? (2012), la mayoría de italianas inició poco a poco a reapropiarse de su legítimo rol social.

En todo caso, Genziana aún tardaría un tiempo en darse cuenta de esta realidad: tras el fallecimiento de sus padres, la protagonista optó por dedicarse al oficio de su madre y ejercer de cafeomante, una profesión para la que

4. Como mérito a los padecimientos bélicos experimentados por la población palermitana, la capital siciliana recibió el 5 de mayo de 1964 la Medalla de Oro al Valor Militar de la República Italiana. 
Un paseo cultural por la representación de palermo en la narrativa de Giuseppina Torregrossa no estaba preparada, de la que tenía nociones rudimentarias, pero que aprovecharía para convencer a sus clientes de la imperante necesidad de votar en favor de la República Italiana. Estimulada por su amado Medoro y segura de que esta forma de estado era la opción más viable para el futuro de Italia, Genziana ensalzaba las ventajas y las excelencias de este sistema gubernamental.

Su labor no cayó en saco roto. La instauración de la República triunfó, si bien esta circunstancia fue posible gracias al apoyo de otras regiones italianas que, a diferencia de la conservadora Sicilia, ${ }^{5}$ secundaron el fin de la monarquía (Torregrossa, 2015 [2013], p. 181). Y como si este advenimiento político hubiera despertado el afán luchador de Genziana por forjar su propia personalidad, la protagonista asumió definitivamente el cargo profesional que siempre había querido desempeñar: jefa de la empresa de café de su difunto padre, un negocio que pasaría a llamar «Caffè Zauditù» en honor a una notoria emperatriz etíope con la que había sido comparada desde su infancia a causa de su oscuro color de piel. ${ }^{6}$ La asunción de este nuevo papel laboral hizo de Genziana uno de los pilares básicos del colectivo femenino de Palermo, donde contrataría a mujeres de su barrio que vieron reconocida de manera paulatina su paridad de género. ${ }^{7}$

Este hecho, sin embargo, no impidió que, como advierte Cancila en Palermo (2014), la mafia palermitana también comenzase a ser partícipe de la especulación inmobiliaria en los años cincuenta del siglo xx, ${ }^{8}$ obteniendo ganancias insospechadas hasta entonces y fortaleciendo su negocio justo en un momento en el que la mafia feudal empezaba a disolverse. Los planes urbanísticos de Palermo dieron cuenta de esta realidad, un proyecto mafioso que conllevó una transformación arquitectónica sin precedentes de la capital siciliana. Los augustos edificios históricos acabarían siendo sustituidos por inmuebles carentes de personalidad, una acción lucrativa que no cambiaría en exceso décadas después (Torregrossa, 2010 [2009], p. 219).

Sirviéndose de créditos bancarios y fondos europeos, los negocios inmobiliarios pasaron a convertirse en una de las principales actividades económicas de Palermo, un modo de proceder que otorgaba enormes réditos financieros y que fomentaba una difusión desmedida de la cultura de la ilegalidad. No obstante, pese al caos cívico y a la pésima situación económica del Mezzogiorno italiano, Torregrossa también plasma en Il conto delle minne el aperturismo femenino del que hacían gala las palermitanas. Según la autora,

[a] Palermo le donne fumano, guidano la macchina, la moto, il camion, indossano le minigonne, i pantaloni, le calze autoreggenti, nuovo simbolo di libertà dopo il collant che aveva sostituito l'odioso reggicalze; siedono al bar, bevono aperitivi, raccontano barzellette, parlano di sesso. (Torregrossa, 2010 [2009], pp. 235-236)

\footnotetext{
5. $\quad$ El comentario de un cliente de Genziana pone de manifiesto el machismo siciliano: «Io ci ho sempre voluto bene al re, che poi è pure masculo. Voi lo sapete che i maschi stanno bene tra di loro, e sapete pure come vanno le cose. Prima di tutto c'è la principessa [...] A seguire la duchessa, la marchesa, la contessa, la baronessa, e alla fine, che non conta più una minchia, a repubbrica: fimmina, manco a dirlo!» (Torregrossa, 2015 [2013], p. 175).

6. Esta comparación tiene un fuerte trasfondo feminista, dado que Zauditù fue la primera mujer africana que se convirtió en cabeza de un estado oficial durante los siglos XIX y XX.

7. No sorprende, pues, que Torregrossa (2015 [2013]) decidiera poner en boca de Viola Olivares, madre de Genziana, las siguientes palabras: «La tua fortuna saranno le femmine, la tua sicurezza il caffè, non te ne scordare mai» (p. 88).

8. Máxime si se tiene en cuenta que en los años 1949-1950 la pobreza de las regiones meridionales no podía ser ignorada, ya que representaba un grave problema de orden público (Colarizi, 2000, p. 336).
} 
Un paseo cultural por la representación de palermo en la narrativa de Giuseppina Torregrossa

Ante esta «libertad» de género, no es de extrañar que las figuras femeninas de las historias de Torregrossa resalten por dar cuenta de su denodada lucha vital. Eso sí, no son los únicos personajes narrativos que muestran la relevancia de modelar la propia identidad. Nacido en la plaza delle Sette Fate de Palermo y personaje destacado de la trama de Cortile Nostalgia, Mario Mancuso deja entrever en su carácter, como sucediera con Genziana, los efectos ocasionados por la prematura pérdida de sus padres. Este fallecimiento une de lleno la acción de este relato con la de La miscela segreta di casa Olivares, pues en ambos casos la falta de referentes paternos es consecuencia directa de los bombardeos que asolaron la ciudad de Palermo en 1943:

Mario era nato lì, a piazzetta delle Sette Fate, in una casa a due piani, con un piccolo giardino, adiacente a un vecchio e pretenzioso palazzo, struppiato dalle bombe. [...] Era rimasto orfano all'età di tre anni, non aveva alcun ricordo dei genitori [...] Zia Ninetta, [fu] l'unica della famiglia sopravvissuta al bombardamento del '43 (Torregrossa, 2017, pp. 11, 13).

Este fragmento pone nuevamente de manifiesto las contrariedades padecidas por los palermitanos, cuyas familias acabaron en su mayoría destrozadas y hundidas tras la Segunda Guerra Mundial. A tenor de esta situación, Mancuso sería criado por su tía Ninetta, una superviviente de aquella sobrecogedora catástrofe que lo abandonaría con tan solo trece años tras fugarse con el que entonces consideraba el amor de su vida. Al igual que Genziana, e incluso con mayor celeridad si cabe, Mancuso no tuvo más remedio que hacerse con el poder de su propia existencia, reinventándola y cincelándola de acuerdo con su nuevo - y absoluto — grado de autonomía.

Icono irremplazable del barrio palermitano de Albergheria, el mercado de Ballarò se convirtió en el espacio literario que forjaría el porvenir de Mancuso. Frente a la habitual carencia de oportunidades, Albergheria brindaba a uno de sus habitantes una ocasión única para labrar su inexorable destino: Mancuso conoció entre las travesías de Ballarò a Melina Scimeca, una joven con la que contraería matrimonio poco tiempo después.

Sin embargo, pese a esta grata sorpresa vital, los esposos pasarían por incesantes dificultades conyugales. Rehuyendo de la «mafiosidad» siciliana ${ }^{9}$ para consagrarse a la política de la legalidad gracias a su profesión de policía, Mancuso empezó su carrera laboral lejos de su tierra natal, alejado de un barrio que, esta vez, en consonancia con muchos otros oriundos de su distrito, no le proporcionaría las herramientas necesarias para desarrollar en él su ocupación. La saudade por su tierra de origen brotó a borbotones en cuanto se hubo trasladado al cuartel Podgora de Roma: la añoranza de Sicilia lo llevaría a mitificar su barrio, ${ }^{10}$ principal escenario narrativo de Cortile Nostalgia. En virtud de ello, parece lógico que el título de la obra se torne una metáfora de la morriña que Mancuso sentía por su lugar de nacimiento, una nostalgia que revelaría su fuerte ligazón con su querida Plaza delle Sette Fate.

9. Conticello en L'isola che c'è (la Sicilia che si ribella al pizzo) (2008), Dickie en Cosa Nostra. Historia de la mafia siciliana (2006), Gambetta en La mafia siciliana. Un'industria della protezione privata (1992) y Sterling en Cosa non solo nostra. La rete mondiale della mafia siciliana (1990) ponen de manifiesto el sectarismo mafioso que caracteriza el territorio insular siciliano.

10. Esta idealización de la isla — no necesariamente positiva en todos los contextos- ha impregnado la producción artística de autores isleños como Sciascia, Verga o Camilleri, de ahí que deba considerarse que este regionalismo literario (y también lingüístico) «ha avuto una manifestazione evidente nella produzione siciliana in cui, però, occorre operare alcune distinzioni, evitando di cadere nella trappola fuorviante di ricorrere [...] allo speculum euristico del tasso di sicilianità/sicilianitudine/sicilianite/sicilianismo»)(Castiglione, 2013, p. 867). 
Un paseo cultural por la representación de palermo en la narrativa de Giuseppina Torregrossa

De todos modos, Mancuso no fue el único personaje que sufrió en primera persona la severidad de la sociedad palermitana del momento. Su esposa Melina también comparte un aspecto vital con Genziana: la necesidad de madurar con tan solo diecisiete años y de enfrentarse a los avatares de ser mujer en Sicilia. A diferencia de Genziana y de su marido, Melina no había perdido a sus padres — quienes, por otra parte, discutían con asiduidad—, sino que se había quedado embarazada después de su primer encuentro sexual con Mancuso. La primera visita de su esposo a Palermo hizo efectivo el contacto íntimo entre la pareja, una relación conyugal insatisfactoria que, en el caso de Melina, culminó con un estado de gravidez fortuito. Inexperta y poco preparada, la situación de Melina parecía análoga a la compleja coyuntura italiana de marzo de 1960:

[La gravidanza] non fu l'unico problema di quell'anno bisestile. A marzo il nuovo governo Tramboni tracciò la sua linea ipocrita e si oppose con ottusa ostinazione a ogni cambiamento. L'atmosfera nell'intero Paese diventò cupa e asfittica. Il battaglione fu consegnato, le licenze sospese per motivi di ordine pubblico. [...] La gente intanto aveva reagito alla repressione del governo con scioperi e manifestazioni. Temevano, i più consapevoli, per quella fragile democrazia che andava nutrita come fosse un neonato sottopeso. [...] Gli scontri per la libertà negata cominciarono al Nord. [...] L'8 luglio a Palermo ci furono [...] morti tra i manifestanti, numerosi feriti, tanti arresti (Torregrossa, 2017, pp. 44-45).

A partir de estas declaraciones, no sorprende que Palermo e incluso Catania se convirtiesen en los núcleos itálicos con mayores altercados (Crainz, 2005, p. 176). Melina daría a luz a su hija Maruzza en esta ardua tesitura nacional, aunque esta neonata, paradójicamente, sería cuidada por la tía Ninetta, aquella mujer que había criado a Mancuso y que ahora volvía a Palermo para hacerse cargo de la niña tras haberse reencontrado con su sobrino en Roma. La situación permaneció inalterada durante cierto tiempo, hasta que, como hiciera antaño, Ninetta se volvió a enamorar. Fascinada por Antonio Taccitedda, antiguo amigo de Mancuso, ${ }^{11}$ Ninetta huyó con él a la capital italiana, si bien, en esta ocasión, prefirió hablar antes de su partida con el párroco de Albergheria: don Gaetano.

Torregrossa se sirve de este hombre para encarnar los valores de la religiosidad siciliana, pero distanciándola del habitual conservadurismo y aproximándola a un progresismo en el que la solidaridad y el altruismo humanos se tornan valores esenciales. La conversación que Ninetta mantiene con don Gaetano le permitiría lograr que su sobrino fuese trasladado a Palermo lo antes posible, una urbe en la que recuperaría aquella alegría de la que Roma le había privado. En esta parte de la trama de Cortile Nostalgia se recurre nuevamente a fuentes históricas para delimitar los acontecimientos de la novela, incluyéndose en el relato a otra de las figuras políticas italianas más insignes desde el final de la Segunda Guerra Mundial: el primer ministro Aldo Moro (Torregrossa, 2017, p. 94). A este respecto, el texto de Torregrossa explicita cómo don Gaetano se puso en contacto con su amigo Aldo Moro, a cuyas órdenes acabaría trabajando Mancuso con carácter previo a su regreso a Palermo.

Durante este periodo el barrio de Albergheria también empezaría a notar significativos cambios sociales, alteraciones palpables en la paulatina llegada de inmigrantes en búsqueda de un futuro mejor (Torregrossa, 2017). En contraste con los palermitanos que abandonaban Albergheria con el propósito de encontrar una mayor

11. Antonio Taccitedda aparece representado en Cortile Nostalgia como un antagonista de Mancuso: a diferencia de este último, que ejercía de policía, Taccitedda trabajaba como extorsionador mafioso. 
Un paseo cultural por la representación de palermo en la narrativa de Giuseppina Torregrossa

prosperidad, los inmigrantes, asolados por la pobreza de sus territorios de origen, hallaban en este barrio un lugar acogedor y agradable en el que asentarse y conseguir que sus hijos y descendientes tuvieran mejores opciones de vida. Por contradictorio que parezca, Torregrossa retrata cómo un mismo espacio urbanístico se conceptualiza de formas antagónicas en función de las circunstancias de cada sujeto: para los oriundos, Albergheria era una zona hostil y desfavorable a sus aspiraciones y a sus proyectos vitales; para los inmigrantes, era el enclave idóneo en el que refundar su porvenir colectivo. Así pues, mientras que para los foráneos la coyuntura política italiana era ajena a sus pretensiones, los palermitanos veían con recelo la cada vez más alarmante situación gubernativa italiana. De esta manera lo plasmaría la autora en la novela de referencia:

Ferruccio Parri [Primo Ministro italiano da giugno a dicembre 1945] tuonava senza pietà contro il capo di Stato maggiore e i Servizi segreti, paventando trame, ricatti e schedature di personaggi illustri. Moro ascoltava con il capo chino e il corpo curvo, gli occhi malinconici fissi su una pila di carte dalla sigla minacciosa: SIFAR [Servizio Informazioni Forze Armate] [...] Momento difficile per lui: c'era in atto una crisi economica subdola, cui aveva cercato di porre rimedio, ma nessuno voleva sentir parlare di risparmio. Ora le indiscrezioni sul Piano Solo e il fallito colpo di Stato intorbidivano le acque limacciose della politica (Torregrossa, 2017, p. 150).

La crisis económica italiana parecía inevitable pese a los intentos políticos por rehuirla. Estudiado por Franzinelli en Il Piano solo (2014), el fallido golpe de estado del militar Giovanni De Lorenzo en 1964 solo serviría para enturbiar el sistema gubernamental italiano, unas circunstancias de las que Mancuso había sido partícipe en primera plana. Dejando su trabajo al servicio de Aldo Moro, el joven policía regresaría al cuartel romano de Podgora ascendido a «Carabiniere scelto», ${ }^{12}$ categoría profesional que posibilitaba su retorno a Palermo en un año. Sin embargo, su frágil estado físico y de salud, derivado de su incapacidad de adaptarse de nuevo al cuartel, facilitó la obtención de un permiso con el que visitar la capital siciliana, una urbe donde su breve estancia se vería afectada por el terremoto que sacudió la ciudad la noche del 14 de enero de 1968 (Abbate \& Di Fede, 2018 , p. 579).

Esta catástrofe natural avivaría el pavor de una población que todavía no se había olvidado de su reciente pasado. A los destrozos de la guerra y a las penurias estatales se unía un nuevo varapalo para la ciudad tras la repentina llegada de este terremoto. El año 1968 acababa de iniciarse y ya revelaba su condición de indómito y tumultuario: las elecciones nacionales italianas se celebrarían el 19 de mayo de 1968, un mes en el que tendrían asimismo lugar las revueltas estudiantiles de Roma como reacción al conocido como «Mayo francés» que Aron y Campi examinan ampliamente en La rivoluzione introvabile (2008). Seis meses más tarde, en concreto el 21 de noviembre de 1968, Aldo Moro pronunciaría su discurso Un'autonoma collocazione politica, una disertación incluida en su obra Il fine è l'uomo (2018) y a la que se alude de forma parcial en la trama narrativa de Cortile Nostalgia (Torregrossa, 2017).

En cualquier caso, esta alocución ayuda a entrever el trasfondo ideológico de Aldo Moro, cuyas consideraciones distaban de las de buena parte de la clase política de su época. La inclusión de esta prédica en Cortile Nostalgia por parte de Torregrossa hace mención explícita al final de un ciclo político y al inicio de un nuevo periodo estatal

12. Segundo grado del Arma de Carabineros, justo por encima de la categoría de «Carabiniere semplice». Reviste el cargo de oficial de policía judicial, así como el de oficial de seguridad pública. 
Un paseo cultural por la representación de palermo en la narrativa de Giuseppina Torregrossa

para los italianos. Mancuso sería partícipe de esta renovada fase, habida cuenta de que, justo el día en que Aldo Moro había dado su discurso, se le comunicaba su traslado definitivo a Sicilia. Mancuso pasaría a trabajar en su querido lugar de nacimiento, Albergheria, una zona que había cambiado sobremanera en los últimos tiempos (Torregrossa, 2017).

La profunda transformación de Albergheria había transmutado el barrio en un distrito cuyos habitantes se mostraban desleales para con los cuerpos de policía: imperaban las acciones ilícitas y las relaciones personales parecían regirse por nuevos códigos ajenos a Mancuso. Pero pese a todo, Mancuso sería ascendido a la categoría de Vicesargento, un puesto que terminaría de envejecerlo por completo. Tanto es así que, en correspondencia con lo acontecido en 1968, Torregrossa también enfatiza, de la mano de Mancuso, el modo en el que se levantaron amplios sectores de la población italiana en 1976. Resultado de la represión experimentada por los ciudadanos italianos, el propio policía no solo sería partícipe de este hartazgo y malestar sociales, sino que además vería en primera persona cómo se sucedieron estas revueltas en Palermo y en el resto de Italia (Torregrossa, 2017).

Buscando refugio en Aldo Moro, Mancuso hallaba consuelo en aquellas figuras políticas que consideraba una válvula de escape a su situación personal. Atemorizado por los eventos que habían bataneado Italia en 1968, no quería verse implicado en un proceso análogo, en una tesitura crítica que tampoco mejoró en 1978 (Torregrossa, 2017). A pesar del ánimo apaciguador de Aldo Moro, el presidente de Democracia Cristiana (DC) acabaría siendo asesinado. Los planes conciliadores de Moro se veían así truncados por los activistas de una época caracterizada por la fuerte presencia del terrorismo de extrema izquierda y de extrema derecha. Italia se adentraría en la conocida como época de los «años de plomo», ${ }^{13}$ un momento de tensos desencuentros entre ambas ideologías políticas.

Pero Palermo, en vez de dejarse imbuir por este contraproducente talante, miraba con optimismo al futuro. Torregrossa exploraría en detalle, a través de los personajes de Cortile Nostalgia, la manera en la que esta ciudad, más allá de sus defectos, logró salir adelante y sobreponerse a la adversidad. De ahí que la escritora haya condensado la esencia de su tierra natal como una urbe tolerante, integradora y bondadosa en los siguientes términos:

[Palermo] che tutti accoglie e tutti assiste; la mamma che tiene aperte le porte anche nella notte, perché non si sa mai se qualcuno arriva; che tiene il fuoco acceso e una pentola a bollire, perché non si sa mai se qualcuno ha fame; che ha sempre lenzuola pulite, perché non si sa mai se qualcuno ha sonno; la mamma che capi la casa quanto voli u patruni. Palermo: la grande madre (Torregrossa, 2017, p. 313).

\subsection{La era contemporánea}

Filippo, Genziana, Mancuso o Melina no son las únicas figuras narrativas que sobresalen por sus firmes convicciones o por su denonada lucha personal. En la producción literaria de Torregrossa también ocupa un puesto destacado Maria Teresa Pajno, más conocida como Marò Pajno, un personaje de ficción que ejerce de policía y que también da cuenta de su perseverante defensa de la igualdad entre sexos. Protagonista de Panza e prisenza, Il basilico di Palazzo Galletti e Il sanguinaccio dell'Immacolata, esta mujer relata sus circunstancias

13. Este periodo histórico ha sido estudiado en profundidad por Baldoni y Provvisionato en Anni di piombo (2009), por Lazar y otros autores en Il libro degli anni di piombo. Storia e memoria del terrorismo italiano (2013), por Montanelli y Cervi en L'Italia degli anni di piombo (1965-1978) (2013), así como por Satta en I nemici della Repubblica: Storia degli anni di piombo (2016). 
Un paseo cultural por la representación de palermo en la narrativa de Giuseppina Torregrossa

vitales dentro de un marco espacio-temporal concreto: sus hazañas se desarrollan en el Palermo de hoy en día. Sin embargo, y siendo más precisos, la acción de Panza e prisenza (2013 [2012]) incide en dibujar las líneas maestras de la sociedad y de la cultura palermitanas. A este respecto, y desde una perspectiva etnográfica, Torregrossa hace una exhaustiva descripción de las fiestas de Santa Rosalía, patrona de Palermo y popularmente apodada «A Santuzza» (Torregrossa, 2013 [2012], pp. 88-89).

El retrato literario de la procesión de Santa Rosalía permite a Torregrossa representar uno de los símbolos clave de la «sicilianidad» palermitana: el fervor religioso de sus conciudadanos hacia la patrona de la ciudad, una santa a la que los palermitanos consideran su más grande salvadora después de que esta hubiera escuchado sus plegarias y les hubiera liberado de la peste que devastó la ciudad de Palermo en 1624. Desde entonces, la conmemoración de esta festividad lleva aparejada una serie de ritos ancestrales profundamente estudiados por Walendziak-Genco (2013, pp. 239-254), ritos entre los que se encuentran los cánticos en honor de Santa Rosalía (Torregrossa, 2013 [2012]).

Consciente de los apasionados cánticos que los fieles entonan a Santa Rosalía, Torregrossa recoge varios versos sicilianos que describen no solo cultural o literariamente la comunidad a la que pertenece, sino que dejan entrever la riqueza lingüística de su territorio y de su ciudad natal: Palermo. Además de su importancia a nivel diatópico y etnográfico, las obras Il basilico di Palazzo Galletti e Il sanguinaccio dell'Immacolata desarrollan toda una serie de acontecimientos que se sitúan en medio de la celebración de festividades religiosas de destacable interés para la sociedad palermitana -y, por extensión, siciliana-. La trama de Il basilico di Palazzo Galletti tiene lugar en Palermo entre el 15 de agosto, día de la Asunción de la Virgen, y el 4 de septiembre, día de Santa Rosalía. De ahí que Torregrossa consiga en su narración trazar de nuevo una fotografía de las más significativas fiestas de la ciudad, reiterando la relevancia palermitana del culto a su patrona, aunque sin renunciar esta vez a hacer alusión a otra celebración basilar para los habitantes de Palermo:

Il 15 di agosto ogni palermitano che si rispetti carica sulla macchina parenti e fornelli e raggiunge il primo spazio verde fuori città. Le macchine bollenti si affollano fin dal mattino presto alle porte della Favorita, ammorbando l'aria del parco; il puzzo dei gas di scarico si somma a quello della carbonella, delle carni messe a cuocere, all'olezzo di cipolla che emana dalle ascelle sudate (Torregrossa, 2018, pp. 57-58).

Evocando este atávico ritual, Torregrossa continúa pormenorizando los aspectos definitorios de la sociedad palermitana, un colectivo que la autora conoce de primera mano y que acerca al lector a través de sus costumbres más enraizadas. La tradición de comer al aire libre el 15 de agosto con familiares y con amigos se suma a otras usanzas no necesariamente ligadas a la época estival. Como se deduce del título, Il sanguinaccio dell'Immacolata menciona explícitamente la festividad de la Inmaculada Concepción, si bien, al igual que a esta fiesta, la trama hace asimismo referencia a la celebración de santa Lucía y al periodo navideño. Inherentes a Palermo, a Sicilia y a todo el espacio y colectivo católicos, estas fechas recogidas por Torregrossa en Il sanguinaccio dell'Immacolata no solo reflejan la impronta religiosa que impregna la producción literaria de esta escritora, sino que también acentúan la religiosidad de la capital siciliana y de toda la isla, en la que los valores cristianos todavía están muy arraigados en el imaginario común. 
Un paseo cultural por la representación de palermo en la narrativa de Giuseppina Torregrossa

De todas maneras, además de este trasfondo cultural, Torregrossa también se sirve de Marò Pajno para reflexionar sobre las trabas a las que se tiene que enfrentar una palermitana que prefiere consagrarse a su carrera profesional en vez de formar una familia y tener hijos. Cuestionándose su rol femenino, Marò Pajno siempre logra ser leal a sus principios, una actitud que configura su personalidad pero que no estaría exenta de riesgos: en Panza e prisenza Marò resolvería con retraso el caso que se le había ordenado, de ahí que, pese a ser conocedora de la verdad, no pudiera validar sus logros a nivel comunitario.

Sin embargo, ascendida a jefa del grupo antifeminicidio de la «Squadra Mobile», ${ }^{14}$ Marò pudo descubrir al culpable del sumario asignado en Il basilico di Palazzo Galletti, una oportunidad magistral para ratificar su valía profesional como mujer. Con todo, de lo que no cabe duda es del ferviente amor que Torregrossa profesa por Palermo, una ciudad a la que, incluso de invierno, esta literata considera una maravilla digna de dioses (Torregrossa, 2019).

\section{Conclusiones}

El análisis de siete de los textos de Torregrossa ha permitido realizar un paseo cultural por la historia de Palermo a través de su producción narrativa. Presa de un territorio que pareciera estar abocado a la involución, Luisa, personaje de $\mathrm{Il}$ conto delle minne, sufrió en primera persona la muerte de su hermano en la matanza de los Fascios de Catalvuturo a finales del siglo XIX. Este acontecimiento en el que se vieron implicadas las masas trabajadoras palermitanas le sirve a Torregrossa para retratar un periodo de fuerte represión que vería su máximo esplendor con la llegada al poder de Mussolini. Filippo, figura clave de Il figlio maschio, es utilizado por la escritora para examinar las singularidades propias del fascismo italiano en Palermo. Representante de una empresa afín al régimen mussoliniano e integrado dentro de la burguesía palermitana, Filippo pone de manifiesto la relevancia de la instrucción y de la difusión de eslóganes publicitarios para construir al perfecto protohombre fascista. Sin embargo, como si fuere consciente de las atrocidades de este contexto histórico, el futuro que Torregrossa depara a este personaje es análogo al de Mussolini: ambos mueren en la Segunda Guerra Mundial.

Las consecuencias de la participación de Italia en este conflicto bélico no se hicieron esperar y Palermo se convirtió en una de las ciudades italianas más devastadas por la contienda. De ahí que, sabedora de los sinsabores de esta coyuntura, Torregrossa enriquezca la trama de La miscela segreta di casa Olivares con pinceladas históricas que dilucidan los entresijos de la vida cotidiana palermitana durante el desarrollo de la guerra. Sirviéndose de Genziana, protagonista de este último relato, pero también de Mancuso, figura destacada de Cortile Nostalgia, la autora recrearía los bombardeos que arrasaron la ciudad de Palermo en 1943. Resultado de estos ataques, Torregrossa dejaría constancia en ambas obras de las penurias sufridas por la población: mientras que Genziana se quedaría huérfana a los diecisiete años, Mancuso perdería a sus padres con tan solo tres. Así, el valor y el ímpetu de estos personajes simbolizarían la robustez palermitana, un vigor que haría de espejo de una sociedad

14. Téngase en cuenta la siguiente acotación: «[1]a Squadra Mobile es un departamento de la policía nacional italiana (Polizia di Stato) con representación en cada prefectura y al que se confían tareas de indagación judicial» (García Fernández, 2019, p. 155). 
Un paseo cultural por la representación de palermo en la narrativa de Giuseppina Torregrossa que lucharía por sus derechos cívicos y humanos.

Y si bien la firma del armisticio con las Fuerzas Aliadas el 3 de septiembre de 1943 contribuyó a que Palermo resurgiese de sus cenizas, sus ciudadanos, conservadores por naturaleza, permanecieron fieles a sus concepciones sociales tras el fin de la Segunda Guerra Mundial. Los palermitanos tuvieron que enfrentarse en 1946 a un evento político sin precedentes: las elecciones generales que determinarían el sistema gubernamental del país y en las que, además, participarían por primera vez las mujeres. Torregrossa daría cuenta en La miscela segreta di casa Olivares de cómo ni la repulsión por la República ni la opresión machista inherentes a la mayor parte de los varones de la urbe sirvieron de nada: Italia dejó de ser una monarquía y las palermitanas no cedieron ante las presiones del patriarcado insular. No sorprende, pues, que Genziana terminase por darse cuenta de su valía personal, decidiendo así convertirse en la jefa de la empresa cafetera de su difunto padre.

La iniciativa profesional de Genziana era comparable a la de Mancuso, quien poco a poco se iría consagrando como policía. A este respecto, nótese cómo, por un lado, Genziana supo dar cuenta de la trascendencia que había de concederse a la paridad de género: la contratación de varias palermitanas de su barrio natal (sororidad) lo pondría de manifiesto. Por otro, Mancuso evidenció la importancia de respetar la cultura de la legalidad, exteriorizando lo menesteroso de frenar el sectarismo mafioso de una ciudad, Palermo, que pareciera estar abandonada a su suerte. La representación literaria de los Quattro Mandamenti y de Albergheria, espacio narrativo de La miscela segreta di casa Olivares y de Cortile Nostalgia respectivamente, responde, por tanto, a un mismo fin: el de reflejar los progresos y las debilidades de sus habitantes, ciudadanos que retratan la etnografía general e inherente a los distritos más identificativos de Palermo.

En relación con la mafia palermitana, Il conto delle minne alude a la especulación inmobiliaria surgida tras el final de la Segunda Guerra Mundial. En un contexto de fuertes penurias económicas, y destrozada por los ataques y bombardeos militares, Palermo necesitaba ser reconstruida prácticamente en su totalidad. Las redes mafiosas —en cierto modo personificadas por Taccitedda, personaje de Cortile Nostalgia - se aprovecharon de esta coyuntura para hacer negocios ilícitos que se desarrollaron durante décadas, un aspecto que, como Torregrossa subraya, contribuyó a una transformación urbanística salvaje en la que los edificios históricos de la urbe fueron reemplazados por inmuebles carentes de personalidad alguna. No obstante, la técnica narrativa que Torregrossa emplearía en Cortile Nostalgia también entrelaza las acciones de la trama con sucesos históricos de gran envergadura para el país transalpino y para la capital siciliana en los años sesenta y setenta del siglo xx: los altercados de Palermo del 8 de julio de 1960, los avatares del primer ministro Aldo Moro (1916-1978), la inmigración y la emigración acontecidas en el barrio palermitano de Albergheria, las desavenencias económicas, el fallido golpe de estado del militar Giovanni De Lorenzo en 1964 o los acontecimientos que tuvieron lugar en Italia a lo largo del año 1968 cementan la base sobre la que Torregrossa entreteje su texto narrativo. Los obstáculos de Mancuso y de su esposa Melina serían análogos a los de Italia en aquel momento, una etapa histórica en cuyo contexto social y político de 1968 acapara toda la atención de la escritora italiana.

La descripción literaria de este panorama nacional italiano y de sus repercusiones en el mayor núcleo poblacional 
Un paseo cultural por la representación de palermo en la narrativa de Giuseppina Torregrossa siciliano se convierten en una táctica estilística gracias a la cual Torregrossa presenta al lector el modo en el que los palermitanos vivieron estas hazañas dentro de sus lindes. Prueba de ello es Cortile Nostalgia, una novela en la que, atenta a los pormenores que caracterizaron el año 1968, Torregrossa describiría: a) las consecuencias del terremoto que sacudió la ciudad de Palermo el 14 de enero de 1968; b) los resultados definitivos de las elecciones nacionales italianas del 19 de mayo de 1968; c) las revueltas estudiantiles romanas de 1968 como reacción derivada del conocido como «Mayo francés»; y d) las particularidades del discurso estatal Un'autonoma collocazione politica pronunciado por Aldo Moro en noviembre de 1968. Torregrossa ligaría esta compleja situación con las dificultades a las que se enfrentó Melina. Al igual que la protagonista de La miscela segreta di casa Olivares, Melina tuvo que madurar con tan solo diecisiete años, haciendo de esta manera frente a una maternidad para la que no estaba preparada y a través de la cual descubriría la verdadera dimensión de ser mujer en Sicilia.

En todo caso, Torregrossa también explota la trama histórica de su novela Cortile Nostalgia para recrear las protestas de la población italiana —incluida, por ende, la palermitana - en 1976, un desasosiego e intranquilidad sociales que nutrirían el estallido de revueltas en Palermo y en el resto de Italia. Y dado que este contexto no mejoró en 1978, Torregrossa actúa parcialmente como historiadora al aproximar a sus leyentes la muerte de Aldo Moro y los «años de plomo», años que marcarían el sino de la nación itálica en la década de los setenta. Sin embargo, el terrorismo de extrema izquierda y de extrema derecha terminaría dando paso a un periodo de mayor paz y estabilidad, unos tiempos de relativo sosiego y armonía en los que Torregrossa se adentra gracias a la creación de un personaje ficcional femenino: Marò Pajno. Protagonista de Panza e prisenza, de Il basilico di Palazzo Galletti y de Il sanguinaccio dell'Immacolata, esta figura literaria no solo reproduce las singularidades que definen el Palermo actual, sino que incluso ahonda en las trabas que todavía hoy debe afrontar una mujer palermitana.

En ambas ocasiones, Torregrossa delinea etnográficamente su ciudad natal: Palermo. Las obras protagonizadas por este personaje así lo ponen de manifiesto al concretar los detalles de sus principales fiestas locales y al sacar a la luz los valores cristianos de la capital de la isla, aún muy arraigados en el imaginario colectivo siciliano. No obstante, ninguna de estas particularidades excluye que la ciudad capitalina, a pesar de sus defectos, haya prosperado y ejerza reiteradamente su papel de «gran madre», una madre, como su patrona, santa Rosalía, dispuesta a acoger y a proteger a las personas sin exclusión ni discriminación alguna. Palermo se revela una urbe única e irrepetible, un panteón de dioses. De ahí que despierte las pasiones anímicas de múltiples intelectuales palermitanas, autoras oriundas que, como Giuseppina Torregrossa, no dudarán un instante en volcar en sus escritos su rendida devoción por la que los fenicios bautizaron como Ziz («flor»), y que la historia consagró al mundo como Palermo. 


\section{Referencias bibliográficas}

1. Abbate, G. \& Di Fede, M. S. (2018). Le città della Valle del Belice in Sicilia a cinquant'anni dal terremoto. En F. Capano et al. (eds.), La Città Altra. Storia e immagine della diversità urbana: Luoghi e paesaggi dei privilegi e del benessere, dell'isolamento, del disagio, della multiculturalità (pp. 579-586). Napoli: Federico II University Press.

2. Aron, R. \& Campi, A. (2008). La rivoluzione introvabile: Riflessioni sul Maggio francese. Soveria Mannelli (Catanzaro): Rubbettino.

3. Baldoni, A. \& Provvisionato, S. (2009). Anni di piombo. Milano: Sperling \& Kupfer.

4. Bellomo, A. (2016). 1943. Il martirio di un 'isola. Zanica (Bergamo): Soldiershop Publishing.

5. Bellomo, A. \& Picciotto, C. (2016). Bombe su Palermo. Cronaca degli attacchi aerei 1940-1943. Zanica (Bergamo): Soldiershop Publishing.

6. Cancila, O. (2014). Palermo (ed. digitale). Roma-Bari: Laterza.

7. Castiglione, M. (2013). Il dialetto nelle esperienze letterarie contemporanee. En G. Ruffino (Ed.), Lingue e culture in Sicilia. Volume II (pp. 866-880). Palermo: Centro di Studi Filologici e Linguistici Siciliani.

8. Ceruso, V. (2015). I 100 delitti della Sicilia. Un appassionante viaggio attraverso i crimini più efferati di un 'isola ricca di fascino e mistero (prima ed. ebook). Roma: Newton Compton Editori.

9. Colarizi, S. (2000). Storia del Novecento italiano. Milano: Rizzoli.

10. Conticello, F. (2008). L'isola che c'è (la Sicilia che si ribella al pizzo). Roma: Round Robin Editrice.

11. Crainz, G. (2005). Storia del miracolo italiano. Culture, identità, trasformazioni fra anni Cinquanta e Sessanta. Roma: Donzelli Editore.

12. Dickie, J. (2006). Cosa Nostra. Historia de la mafia siciliana (trad. de F. Ramos). Barcelona: Debate.

13. Franzinelli, M. (2014). Il Piano Solo. I servizi segreti, il centro-sinistra e il "Golpe» del 1964. Milano: Mondadori.

14. Gambetta, D. (1992). La mafia siciliana. Un'industria della protezione privata. Torino: Einaudi.

15. García Fernández, J. (2019). Giuseppina Torregrossa: Espejo literario y cultural de Sicilia. Canterano (Roma): Aracne.

16. Giangrande, A. (2016). L'invasione barbarica sabauda del Mezzogiorno d'Italia. California: CreateSpace. 17. Lazar, M. et al. (2013). Il libro degli anni di piombo. Storia e memoria del terrorismo italiano (trad. de C. Delorenzo \& F. Peri). Milano: Rizzoli.

18. Lecco, E. (1981). Francesco Ciarlantini. En A. M. Ghisalberti (dir.), Dizionario biografico degli italiani. Vol. 25: Chinzer Cirni (pp. 214-216). Roma: Istituto della Enciclopedia Italiana. Recuperado de http://www.treccani. it/enciclopedia/francesco-ciarlantini_(Dizionario-Biografico)/

19. Melograni, P. (2010). Italia in guerra. 10 giugno 1940. Venezia: Marsilio.

20. Montanelli, I. \& Cervi, M. (2013). L’Italia degli anni di piombo (1965-1978). Milano: Rizzoli. 
Un paseo cultural por la representación de palermo en la narrativa de Giuseppina Torregrossa

21. Moro, A. (2018). Il fine è l'uomo. Roma-Ivrea: Edizioni di Comunità.

22. Rossi-Doria, A. (1996). Diventare cittadine: Il voto delle donne in Italia. Firenze: Giunti Editore.

23. Sarlo, A. \& Zajczyk, F. (2012). Dove batte il cuore delle donne? Voto e partecipazione politica in Italia. Roma-Bari: Laterza.

24. Satta, V. (2016). I nemici della Repubblica: Storia degli anni di piombo. Milano: Rizzoli.

25. Sterling, C. (1990). Cosa non solo nostra. La rete mondiale della mafia siciliana (trad. de R. Rambelli). Milano: Mondadori.

26. Torregrossa, G. (2010 [2009]). Il conto delle minne. Milano: Mondadori.

27. Torregrossa, G. (2013 [2012]). Panza e prisenza. Milano: Mondadori.

28. Torregrossa, G. (2015 [2013]). La miscela segreta di casa Olivares. Milano: Mondadori.

29. Torregrossa, G. (2015). Il figlio maschio. Milano: Rizzoli.

30. Torregrossa, G. (2017). Cortile Nostalgia. Milano: Rizzoli.

31. Torregrossa, G. (2018). Il basilico di Palazzo Galletti. Milano: Mondadori.

32. Torregrossa, G. (2019). Il sanguinaccio dell'Immacolata. Milano: Mondadori.

33. Walendziak-Genco, E. (2013). Festa patronale di santa Rosalia di Palermo - Storia e folklore. Kwartalnik Neofilologiczny, 60(2), 239-254. Recuperado de http://journals.pan.pl/Content/88624/mainfile.pdf?handler=pdf 